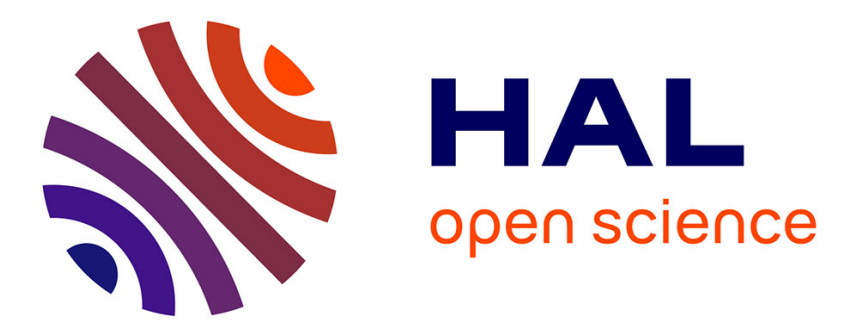

\title{
The Fifteenth International Workshop on Collaborative Editing Systems
}

\author{
Michael S. Macfadden, Agustina Ng, Claudia-Lavinia Ignat, Ning Gu, \\ Chengzheng Sun
}

\section{- To cite this version:}

Michael S. Macfadden, Agustina Ng, Claudia-Lavinia Ignat, Ning Gu, Chengzheng Sun. The Fifteenth International Workshop on Collaborative Editing Systems. IWCES'17 - The Fifteenth International Workshop on Collaborative Editing Systems, Feb 2017, Portland, United States. ACM, 2017, $10.1145 / 3022198.3022653$. hal-01652759

\section{HAL Id: hal-01652759 \\ https://hal.inria.fr/hal-01652759}

Submitted on 30 Nov 2017

HAL is a multi-disciplinary open access archive for the deposit and dissemination of scientific research documents, whether they are published or not. The documents may come from teaching and research institutions in France or abroad, or from public or private research centers.
L'archive ouverte pluridisciplinaire HAL, est destinée au dépôt et à la diffusion de documents scientifiques de niveau recherche, publiés ou non, émanant des établissements d'enseignement et de recherche français ou étrangers, des laboratoires publics ou privés. 


\section{The Fifteenth International Workshop on Collaborative Editing Systems}

\author{
Michael S. MacFadden \\ SOLUTE Consulting, USA \\ macfadden.michael@solute.us

\section{Agustina Ng} \\ School of Computer Science and \\ Engineering, \\ Nanyang Technological University, \\ Singapore \\ agustina@ntu.edu.sg \\ Claudia-Lavinia Ignat \\ LORIA-Inria Nancy-Grand Est, \\ France \\ claudia.ignat@inria.fr

\section{Ning Gu} \\ School of Computer Science, \\ Fudan University, Shanghai, China \\ ninggu@fudan.edu.cn

\section{Chengzheng Sun} \\ School of Computer Science and \\ Engineering, \\ Nanyang Technological University, \\ Singapore \\ czsun@ntu.edu.ss
}

Permission to make digital or hard copies of part or all of this work for personal or classroom use is granted without fee provided that copies are not made or distributed for profit or commercial advantage and that copies bear this notice and the full citation on the first page. Copyrights for third-party components of this work must be honored. For all other uses, contact the Owner/Author.

Copyright is held by the owner/author(s).

CSCW '17 Companion, February 25 - March 01, 2017, Portland, OR, USA ACM 978-1-4503-4688-7/17/02

http://dx.doi.org/10.1145/3022198.3022653

\begin{abstract}
Not long ago, real time collaborative editing (CE)

systems were seen as a novelty to the average user, and a niche area of computer science research. Today, nothing could be further from the truth. Users are increasingly more connected and are creating more and more content online, on mobile devices, and in cloud based applications. Users are increasingly expecting collaborative editing functionalities in all of their applications.

The focus of this year's workshop is: 1 ) to explore recent advances in the technologies that enable collaborative editing systems, 2 ) to evaluate the adoption of these technologies by commercial industry and the open source communities, and 3) to foster an exchange of ideas between CE researchers and enduser CE systems builders. The goal is to increase the adoption of recent technological advancements in CE research by practitioners and to have practitioners identify real-world challenges for future research.
\end{abstract}

\section{Author Keywords}

Collaborative editing systems; groupware.

\section{ACM Classification Keywords}

C.2.4. Computer-Communication Networks: Distributed Systems - Distributed applications; H.1.2. Models and Principles: User/Machine Systems - Human factors; 
H.4.1. Information Systems Applications: Office Automation - Groupware; H.5.3. Information Interfaces and Presentation: Group and Organization Interfaces; I.7.1. Document and Text Processing: Document and text editing.

\section{Introduction}

Collaborative Editing (CE) systems allow users to create and edit content together even though they may be in physically disparate locations. A decade ago, $\mathrm{CE}$ systems that provided real-time collaborative editing were a niche market, and research into this area was limited to a small segment within the field of Computer Science. Today, the world is seeing an exposing in interest in CE. There is widespread end-user interest in $\mathrm{CE}$, and a large number of developers and researchers are becoming increasingly familiar with the underlying science and enabling technologies.

High-speed broadband network access is becoming increasingly common across the globe, strongly connecting users across large geographic distances. Simply put, the world is becoming more and more connected every day. Cloud computing services such as Amazon Web Services ${ }^{1}$, Google Compute Engine ${ }^{2}$, Digital Ocean ${ }^{3}$, and Microsoft Azure ${ }^{4}$ (among others), are making it easier and more cost effective to build and deploy Internet scale applications.

Application vendors and service providers are working at a feverish pace to migrate from isolated desktop

\footnotetext{
${ }^{1}$ https://aws.amazon.com/

2 https://cloud.google.com/compute/

${ }^{3}$ https://www.digitalocean.com/

${ }^{4}$ https://azure.microsoft.com
}

applications, to cloud enabled web-based and hybrid applications. Furthermore, the ubiquity of powerful mobile devices and high speed cellular networks means that users have almost uninterrupted access to their data and digital lives. Together, these advances have driven a cultural shift towards "sharing". Today we can share and access our pictures, videos, documents, even our thoughts at the click of a button, from anywhere.

The next evolution of these systems is now upon us. Users are realizing that while they have almost unlimited access to their data and that sharing is easy, the number of applications that allow collaborative editing is still relatively small. Sharing with each other is fantastic, but today's users desperately want to create together. A significant number of large corporations including Google, Microsoft, Apple, and Salesforce have realized this and are spending significant resources to deliver CE capabilities within their products. Many other application developers have taken note of these industry leaders and are also now exploring CE features.

While a significant body of research exists, creating a robust CE system that meets users' expectations is challenging. Concurrency control, distributed data structures, reliable messaging, user experience design, system performance tradeoffs, scalability, fault tolerance, and domain specific semantics all present real world challenges in developing a usable CE system. These challenges have not gone unnoticed by CE system builders, and they are increasingly looking to the CE research community for theories, technologies, experiences, and assistance to build the next generation of collaborative applications. 
This workshop is a key mechanism for CE researchers and CE system builders to share information in order to increase the adoption of CE research into commercial industry and open source communities, and to provide feedback to the CE research community on the current issues faced when building real world systems.

\section{Theme}

This workshop builds on the success of the previous fourteen workshops. The theme of each workshop evolved over time to focus on the current issues surrounding collaborative editing based on new research, technological advancements in computing and networking, and socio-technological changes impacting the way users interact with computer supported cooperative systems.

The theme of this year's workshop is two-fold. First, it is an excellent time to take stock of the increasingly rapid adoption of collaborative editing by commercial industry and the open source community. By evaluating the success that CE systems are starting to enjoy, the community can evaluate the most popular use cases, and identify trends (both good and bad) in how collaborative features are being delivered to end-users. Second, the bulk of the workshop will focus on an exchange of information between developers of $\mathrm{CE}$ systems and those performing foundational and applied research in the CE domain.

\section{Goals}

Historically, information has flowed one way, from the research community to the commercial and open source software world; primarily through conferences and journal publications. Outside of these workshops, the information flow from industry back to the $\mathrm{CE}$ research community has been limited. The main goals of the workshop are to promote bilateral information sharing between industry and researchers. The continued dialog will help ensure that industry is aware, and can make use of recent research. Conversely, researchers will have the opportunity to learn more about the current issues industry faces in delivering CE capabilities to their users. Finally, researchers have the opportunity to discuss their current research and preliminary findings in an informal setting to get feedback from the broader community. Together, achieving these goals will help with the advancement of CE research and the adoption of collaborative systems throughout industry.

\section{Topics}

Collaborative editing is a wide field of study. Topics of interest in this workshop include, but are not limited to:

- Concurrency control and consistency maintenance

- Distributed conflict resolution strategies

- Correctness of CE systems

- Performance and scalability of CE methods

- Collaborative visualization and user experience

- Demonstrations of new systems

- Current challenges in real world systems

- Industry trends in CE

\section{Organizers}

The organizers of this workshop possess significant commercial and academic experiences in researching and developing CE systems. The organizers have successfully held a CE workshop at 14 previous conferences, most of which were held at CSCW. 
Michael S. MacFadden

CTO, SOLUTE, InC.

San Diego, CA, USA

Michael MacFadden is the Chief Technology Officer for SOLUTE, Inc. and is the lead architect of collaborative software solutions developed in coordination with the United States Department of Defense. He has a M.S. in

Computer Science and specializes in distributed systems. He is a member of the Apache Software Foundation, serving as both a software architect and as a member of the Project

Management Committee for the Apache Wave Incubator project, which is a real-time, rich, web collaboration platform based on Operational Transformation. Through these activities, he has deeply explored the technical, cognitive, and social aspects of distributed real-time collaboration.

\section{Agustina Ng}

School of Computer Science and Engineering,

Nanyang Technological University, Singapore

Dr. Agustina $\mathrm{Ng}$ is a research fellow at Nanyang

Technological University, Singapore. She received her PhD degree in 2012 from the School of Computer Engineering at Nanyang Technological University, Singapore. Her research interest spans from computer supported cooperative work, distributed systems, human-computer interaction, to 3D telepresence. Her current work focuses on devising advanced real-time collaborative technologies, such as Transparent Adaptation, Operational

Transformation, and workspace awareness supporting techniques, for real time collaborative editing of 3D design documents (CoMaya project), complex editing of plain-text documents (CoVim project), workspace managements, etc.

\section{Claudia-Lavinia Ignat}

Inria Research Scientist CR1

Coast team / LORIA-Inria Nancy-Grand Est, France

Claudia-Lavinia Ignat is a permanent researcher at Inria in France. She obtained her PhD in Computer Science from ETH Zurich, Switzerland in 2006. Her research interests are distributed collaborative systems with a focus on consistency maintenance, group awareness, security, trust issues and user studies. She is in the editorial board of Journal of CSCW and program committee member of several international conferences such as CSCW, GROUP, CDVE and ICEBE. She coordinated or was involved in several research and industrial projects.

\section{Ning Gu}

School of Computer Science, Fudan Univ., Shanghai, China Prof. Ning Gu is a full professor in school of computer science at Fudan University. His research interests include data consistency, data analysis, social, and technical combination research on specific domain, currently he is more interested in two application domains on saving energy and the disabled/seniors. Prof. Gu works in the area of Computer Supported Cooperative Work (CSCW), Cooperative and Social Computing, and has published over 130 papers in the key international and national journals and conferences such as CHI, CSCW, WWW, GROUP,

ICDCS, TPDS, his lab now becomes a leading CSCW lab in China. He is Director of Fudan Social Computing Research Center, director of Cooperative Information and Systems Laboratory. He also serves as Director of Cooperative Computing Committee of China Computer Federation (CCF), Director of Cooperative Computing Committee of Shanghai Computer Federation.

\section{Chengzheng Sun}

School of Computer Science and Engineering,

Nanyang Technological University, Singapore Dr. Chengzheng Sun is a Professor at Nanyang Technological University, Singapore. Before he moved to Singapore, he was a Professor at Griffith University, Australia. Previously, he worked in Changsha Institute of Technology, University of Amsterdam, Phillips Research Labs Eindhoven, and ACE in Amsterdam, for over 15 years in the areas of distributed and parallel computing systems. His current research lies at the intersections of ComputerSupported Cooperative Work, distributed systems, humancomputer interaction, and software engineering. Major applications of his research include collaborative office productivity tools, collaborative computer-aided design and engineering tools, and collaborative digital media design tools. Dr. Sun is the leader and chief investigator of REDUCE, CoWord, CoPowerPoint, CoMaya, CoVim, and OTXplorer projects. Dr. Sun is one of the co-founders of this CE workshop series. 